The new Hall of North American Mammals, although far from completed, is yet an imposing example of the blending of many arts, many sciences, and the most modern methods of museum architecture, exhibition and lighting. It is $140 \mathrm{ft}$. in length by $73 \mathrm{ft}$. in width and built in the form of an ' $T$ ' with parallel aisles flanking each side of the central corridor, which extends the length of the hall. The habitat groups are recessed along the corridor and at both ends. The lighting represents the result of careful study to relieve eye-strain and to provide a restful atmosphere, with the illumination directed towards the exhibits and away from the visitor.

The backgrounds of the exhibits present a panorama of the North American continent, from Ellesmere Land, 700 miles south of the North Pole, to Mexico, and from New York State to the west coast of Alaska, with the mammals characteristic of each region. The skilled preparation of both backgrounds and specimens was the work of many artists and taxidermists under the direction of Dr. James L. Clark, head of the Museum's Department of Preparation.

The achievement of the Hall itself was due to Dr. Anthony's continuous and enthusiastic efforts, to the sympathetic understanding and aid of President F. Trubee Davison, and to the co-operation of the officials of the City of New York. The magnificent animals were collected and presented by friends of the Museum, and when all groups are installed there will be a complete series of the most characteristic mammals of the entire continent of North America. The finished groups include the Alaska brown bear, the largest carnivorous land mammal in existence, the bighorn sheep, white (mountain) sheep, Grant caribou, muskox (collected by Admiral Peary), mountain goat, Osborn caribou, Alaska moose, grizzly bear and mountain lion (puma). Nineteen groups remain to be installed, eight of these to be opened in the near future, including the bison, wapiti, Virginia deer, jaguar and various small mammals, which are also to be represented in the hall.

\section{INTERNATIONAL TABLE OF STABLE ISOTOPES}

\footnotetext{
$\mathrm{T}$ HIS Table, together with the Fifth Report of the Committee on Atoms, was last published, in Paris, by the Union Internationale de Chimie just before the occupation of France. After that event Prof. E. Briner of Geneva very kindly offered to undertake the correspondence necessary to continue the work of the Committee. With his help I was able, as chairman, to draw up a Sixth Report which I submitted to him for publication early in 1941 . Later in that year he informed me that unfortunately he had been unable to arrange for its publication, and requested me to draw up a modified report brought up to date for 1941-1942. This I did, and in February 1942 he wrote that I might soon expect the proofs of this. I have heard nothing from him since, and as I think further delay would be unfortunate, the report is appended. There has been very little published on the subject since it was drawn up and, so far as I have been able to ascertain, the other members of the Committee approve of all the alterations embodied in it. F. W. Aston.

Trinity College,

Cambridge.

Oct. 5.
}

\section{Sixth Report of the Committee on Atoms of the International Union of Chemistry}

Chairman: F. W. Aston. Members : N. Bohr, O. Hahn, W. D. Harkins, F. Joliot, R. S. Mulliken, M. L. Oliphant.

Owing to the impossibility of publication during 1941, this report covers double the normal period. The following changes in the Table of Isotopes are recommended :

Helium. Evidence has been obtained by means of the cyclotron that a stable isotope of mass 3 exists in Nature ${ }^{1}$. The abundance is very small and is estimated at about $10^{-7}$ per cent.

Sulphur. The parentheses indicating doubt in the existence of the very rare isotope 36 are to be removed.

Nickel. Two complete electrometric analyses have now been published, by Straus ${ }^{2}$ and Valley ${ }^{3}$. Their results are given below together with those obtained in the original photometric observations ${ }^{4}$ :

$\begin{array}{lrrccc}\text { Mass numbers } & 58 & 60 & 61 & 62 & 64 \\ \text { Aston (1935) } & 67 \cdot 5 & 27 \cdot 0 & 1 \cdot 7 & 3 \cdot 8 & ? \\ \text { Straus } & 62 \cdot 8 & 29 \cdot 5 & 1 \cdot 7 & 4 \cdot 7 & 1 \cdot 3 \\ \text { Valley } & 67 \cdot 4 & 26 \cdot 7 & 1 \cdot 2 & 3 \cdot 8 & 0 \cdot 88\end{array}$

Valley's work is approved by Bainbridge. His figures are in better agreement with the photometric results, and also with the chemical atomic weight, than are those of Straus. Both observers agreo that 61 is 1.3 times more abundant than 64 . This is in good accord with the mass spectra previously obtained by Dempster ${ }^{5}$ and also with the original ones of Aston (re-examined) upon which the previous figures were based, but contradicts the evidence of the parabolas from which Lub" deduced that 61 is "with regard to 64 as $1: 10$ ". Valley's figures are now adopted.

Cobalt. In consequence of doubts expressed on many grounds as to the existence of a stable isotope 57, Mitchell, Brown and Fowler ${ }^{7}$ have analysed $\mathrm{CoCl}_{2}$ with a mass spectrometer. Their results show that 57 cannot be present even to 1 in 30,000 of 59 . As in mass spectrometry evidence of absence is much more cogent than that of presence, cobalt is now to be regarded as a simple element.

Molybdenum. Electrometric measurements on this element have been carried out by Valley ${ }^{8}$. The following percentages, which he considers accurate to one per cent, are recommended :

$\begin{array}{lccccccc}\text { Mass numbers } & 92 & 94 & 95 & 96 & 97 & 98 & 100 \\ \text { Abundances } & 14 \cdot 9 & 9 \cdot 40 & 16 \cdot 1 & 16 \cdot 6 & 9 \cdot 65 & 24 \cdot 1 & 9 \cdot 25\end{array}$

They show a satisfactory small divergence from the photometric ones of Mattauch and Lichtblau, adopted in the previous report, and the original ones of Aston, and lie roughly between the two.

Rhodium. The rare isotope 101 of rhodium is subject in considerable degree to the same objections as that of cobalt above mentioned. It will therefore be regarded as doubtful, and given in parentheses, until further experimental evidence is available.

${ }^{1}$ Alvarez, L. W., and Cornog, R., Phy8. Rev., 56, 379 (1939).

Straus, H. A., Phys. Rev., 59, 430 (1941).

Valley, G. E., Phys. Rev., 59, 836 (1941).

Aston, F. W., Proc. Roy. Soc., A, 149, 396 (1935).

s Dempster, A. J., Phys. Rev., 50, 98 (1936).

- Lub, W. A., Proc. Roy. Soc. Amsterdam, 42, 253 (1939).

' Mitchell, J. J., Brown, H. S., and Fowler, R. D., Phys. Rev., 60, 359 (1941).

- Valley, G. E., Phys. Rev., 57, 1058 (1940). 